\title{
Removal of Polyvinyl Alcohol Using Photoelectrochemical Oxidation Processes Based on Hydrogen Peroxide Electrogeneration
}

\author{
Kai-Yu Huang, ${ }^{1}$ Chih-Ta Wang, ${ }^{2}$ Wei-Lung Chou, ${ }^{3}$ and Chi-Min Shu' \\ ${ }^{1}$ Department of Safety Health and Environmental Engineering, National Yunlin University of Science and Technology, \\ Yunlin 64002, Taiwan \\ ${ }^{2}$ Department of Safety Health and Environmental Engineering, Chung Hwa University of Medical Technology, Tainan City 717, Taiwan \\ ${ }^{3}$ Department of Safety, Health and Environmental Engineering, Hungkuang University, Shalu, Taichung 433, Taiwan
}

Correspondence should be addressed to Wei-Lung Chou; wlchou@sunrise.hk.edu.tw

Received 25 June 2013; Revised 1 August 2013; Accepted 1 August 2013

Academic Editor: Mika Sillanpaa

Copyright (C) 2013 Kai-Yu Huang et al. This is an open access article distributed under the Creative Commons Attribution License, which permits unrestricted use, distribution, and reproduction in any medium, provided the original work is properly cited.

\begin{abstract}
This study investigates the removal efficiency of PVA from aqueous solutions using UV irradiation in combination with the production of electrogenerated hydrogen peroxide $\left(\mathrm{H}_{2} \mathrm{O}_{2}\right)$ at a polyacrylonitrile-based activated carbon fiber (ACF) cathode. Three cathode materials (i.e., platinum, graphite, and ACF) were fed with oxygen and used for the electrogeneration of $\mathrm{H}_{2} \mathrm{O}_{2}$. The amount of electrogenerated $\mathrm{H}_{2} \mathrm{O}_{2}$ produced using the ACF cathode was five times greater than that generated using the graphite cathode and nearly 24 times greater than that from platinum cathode. Several parameters were evaluated to characterize the $\mathrm{H}_{2} \mathrm{O}_{2}$ electrogeneration, such as current density, oxygen flow rate, solution $\mathrm{pH}$, and the supporting electrolyte used. The optimum current density, oxygen flow rate, solution $\mathrm{pH}$, and supporting electrolyte composition were found to be $10 \mathrm{~mA} \mathrm{~cm}{ }^{-2}, 500 \mathrm{~cm}^{3} \mathrm{~min}^{-1}, \mathrm{pH}$ 3 , and $\mathrm{Na}_{2} \mathrm{SO}_{4}$, respectively. The PVA removal efficiencies were achieved under these conditions $3 \%, 16 \%$, and $86 \%$ using UV, $\mathrm{H}_{2} \mathrm{O}_{2}$ electrogeneration, and $\mathrm{UV} / \mathrm{H}_{2} \mathrm{O}_{2}$ electrogeneration, respectively. A UV light intensity of $0.6 \mathrm{~mW} \mathrm{~cm}{ }^{-2}$ was found to produce optimal PVA removal efficiency in the present study. A simple kinetic model was proposed which confirmed pseudo-first-order reaction. Reaction rate constant $\left(k_{\mathrm{ap}}\right)$ was found to depend on the UV light intensity.
\end{abstract}

\section{Introduction}

Advanced oxidation processes (AOPs) have become very common for the treatment of industrial wastewater containing organic compounds. AOPs are based on the generation of highly reactive radicals such as hydroxyl $\left({ }^{\circ} \mathrm{OH}\right)$, a strong oxidant with $E$ of $2.8 \mathrm{~V}$, which can be strong enough to nonselectively oxidize most organic compounds through chain reactions at ambient temperature and pressure. Among these AOPs, electrochemical oxidation is thought to be one of the most promising methods for wastewater treatment; it is friendly to the environment, easy to control, and efficient for oxidation [1]. The electrochemical oxidation of organic pollutants is generally accompanied by side reactions such as oxygen or chlorine evolution due to the high voltage required to destroy the organic compounds in aqueous solutions.
Thus, it may prove more efficient to combine electrochemical oxidation with other processes $[2,3]$. Ultraviolet (UV) photolysis is another effective process. UV-based AOPs are characterized by the generation of strong oxidizing species, principally hydroxyl radicals, using combinations of strong oxidizing agents, such as ozone and hydrogen peroxide $\left(\mathrm{H}_{2} \mathrm{O}_{2}\right)$ with UV radiation in the 200-280 $\mathrm{nm}$ range $[4,5]$.

Hydrogen peroxide $\left(\mathrm{H}_{2} \mathrm{O}_{2}\right)$ is an environmentally friendly chemical, because it leaves no hazardous residues. It is a powerful and versatile chemical, because it reacts as both a reductant and an oxidant [6]. However, the oxidative power of hydrogen peroxide is not strong enough to degrade organic compounds in some cases. Application in conjunction with UV irradiation and a metal catalyst can effectively increase the oxidative power of hydrogen peroxide due to the production of hydroxyl free radicals. The putative mechanism 
for the photolysis of $\mathrm{H}_{2} \mathrm{O}_{2}$ is the cleavage of the molecule into hydroxyl free radicals, which can then oxidize organic compounds $(\mathrm{RH})$, yielding organic radicals that can in turn carry out further oxidation. The reactions that are accepted to occur during the $\mathrm{UV} / \mathrm{H}_{2} \mathrm{O}_{2}$ oxidation process are as follows [7]:

$$
\begin{gathered}
\mathrm{H}_{2} \mathrm{O}_{2}+\mathrm{UV} \longrightarrow 2^{\circ} \mathrm{OH} \\
\mathrm{RH}+{ }^{\circ} \mathrm{OH} \longrightarrow \mathrm{H}_{2} \mathrm{O}+\mathrm{R}^{\bullet} \longrightarrow \text { further oxidation }
\end{gathered}
$$

Employing $\mathrm{H}_{2} \mathrm{O}_{2}$ with UV radiation for the removal of aqueous estrogens is one example of a homogeneous advanced oxidation process. The in situ electrochemical production of $\mathrm{H}_{2} \mathrm{O}_{2}$ via the reduction of oxygen on a cathode can reduce the costs and hazards associated with the transport and handling of concentrated $\mathrm{H}_{2} \mathrm{O}_{2}$. In recent years, some combinations of electrochemical oxidation and photolysis had been reported by various researchers [8, 9]. Most of these researchers concentrated on electro-Fenton technology in combination with UV irradiation, which may facilitate the photodecomposition of organic compounds, increase the generation of hydroxyl free radicals, and regenerate $\mathrm{Fe}^{2+}$ from $\mathrm{Fe}^{3+}$ species through a photoreduction mechanism [10-13]. However, there is little research on the combination of $\mathrm{H}_{2} \mathrm{O}_{2}$ electrogeneration with direct photolysis in the absence of added catalysts such as $\mathrm{Fe}^{2+}$ and $\mathrm{TiO}_{2}$.

Electrochemical production of $\mathrm{H}_{2} \mathrm{O}_{2}$ has traditionally used graphite electrodes because of their low cost [14]. However, the poor solubility of oxygen in aqueous solutions causes mass transfer limitation, resulting in lower oxidation efficiency. Recently, activated carbon fiber (ACF) has been recognized as a promising carbon material with excellent characteristics for adsorption, conductivity, and catalysis [15]. Because of its large surface area, ACF also exhibits a high adsorption capacity and high adsorption rates. The excellent mechanical integrity of ACF makes it easy to configure as a stable electrode at which electrosorption processes can be conducted for the purpose of adsorptive removal of various organic pollutants in aqueous solutions. Furthermore, ACF electrodes may be used for the electrogeneration of $\mathrm{H}_{2} \mathrm{O}_{2}$ via the two-electron reduction of oxygen on its surface $[16,17]$. The $\mathrm{H}_{2} \mathrm{O}_{2}$ electrogeneration rate significantly affects the treatment efficiency of any electro-Fenton technology. Several series processes affect the electrogeneration rate of $\mathrm{H}_{2} \mathrm{O}_{2}$ [15-17]. Oxygen gas must first be dissolved in solution. Second, it must be transferred to cathode surface, adsorbed onto the cathode, and finally reduced electrochemically to produce $\mathrm{H}_{2} \mathrm{O}_{2}$ in acidic media. Possible side reactions may occur simultaneously at the cathode and thus decrease the electrogeneration rate of $\mathrm{H}_{2} \mathrm{O}_{2}$ [14].

Polyvinyl alcohol (PVA) is frequently used in the textile industry in blends with nylon and as a raw material for the production of PVA fibers. In addition, PVA is used as an ophthalmic lubricant in the pharmaceutical industry and is also widely used in the adhesives, emulsion paints, paper coating, and detergent-based industries. It is generally recognized that PVA is a high-k polymer with interesting properties such as good surface alignment effects, compatibility with water, low cost, and inexpensive processing [18].
The large amount of PVA discharged in industrial effluents is harmful to human health and to the environment [19]. It is often difficult to clean wastewaters containing PVA and to generate harmless end products such as water and carbon dioxide; thus, PVA adversely affects the ecosystem and accumulates in the human body through the food chain. PVA also creates environmental issues due to its ability to prevent the sedimentation of heavy metals in lakes and streams. Conventional biological technologies do not provide effective treatment of PVA because the degradation capacity of most microorganisms towards PVA is extremely low and specific to PVA [20]. The formation of foam in biological equipment for the treatment of wastewater containing PVA also makes stable operations and acceptable performance very difficult. A large number of scientific studies on the removal of PVA have been carried out, most of which have focused on photochemically initiated degradation processes [21]. Other physicochemical studies on the removal of PVA have focused on methods such as ultrasonic techniques [22], radiation-induced degradation [23], electro-Fenton [17], adsorption by activated carbon [24], and electrocoagulation $[25,26]$.

To our knowledge so far, very little work, if any, has been reported in the literature to date on PVA removal by photoelectrochemical oxidation processes based on $\mathrm{H}_{2} \mathrm{O}_{2}$ electrogeneration. The main purpose of this study was to investigate the efficiency of $\mathrm{H}_{2} \mathrm{O}_{2}$ electrogeneration in acidic solutions using different cathodes fed with oxygen and to elucidate the removal efficiency of PVA via photoelectrochemical oxidation using an ACF cathode. The influences of several operating parameters such as current density, oxygen flow rate, solution $\mathrm{pH}$, and different supporting electrolytes on the $\mathrm{H}_{2} \mathrm{O}_{2}$ electrogeneration were investigated. The effects of different processes ( $\mathrm{UV}, \mathrm{H}_{2} \mathrm{O}_{2}$ electrogeneration, and $\mathrm{UV} / \mathrm{H}_{2} \mathrm{O}_{2}$ electrogeneration), and $\mathrm{UV}$ irradiation intensity on the rate of PVA removal from aqueous solutions were also investigated. In addition, a simple kinetic model for PVA removal by photoelectrochemical oxidation was proposed to calculate the reaction rate constant.

\section{Experimental}

2.1. Material and Chemical Reagents. Polyvinyl alcohol (PVA, molecular weight in the range of 13,000 to $23,000 \mathrm{~g} \mathrm{~mol}^{-1}$ ) was obtained from Sigma-Aldrich (Saint Louis, MO 63103, USA) with a hydrolysis degree ranging from 98 to $99 \%$. $\mathrm{Na}_{2} \mathrm{SO}_{4}, \mathrm{NaNO}_{3}$, and $\mathrm{NaCl}$ were purchased from Merck (Darmstadt, Germany) and used as supporting electrolyte in the aqueous solutions. Titanium(IV) sulfate $\left[\mathrm{Ti}\left(\mathrm{SO}_{4}\right)_{2}\right]$ was purchased from SHOWA (Tokyo, Japan). Potassium iodide (KI) was obtained from Union Chemical Work Ltd. (HsinChu, Taiwan), and iodine (I) was obtained from Toyobo Co. Ltd. (Osaka, Japan). Boric acid $\left(\mathrm{H}_{3} \mathrm{BO}_{3}\right)$ was purchased from Merck (Darmstadt, Germany). Sulfuric acid $\left(\mathrm{H}_{2} \mathrm{SO}_{4}, 3 \mathrm{M}\right)$ was used to adjust the $\mathrm{pH}$ of the solution. All chemicals were analytical grade reagents and prepared by dilution with deionized water to the desired concentrations. The activated carbon fiber (ACF), PAN-based rigid composite carbon felt 


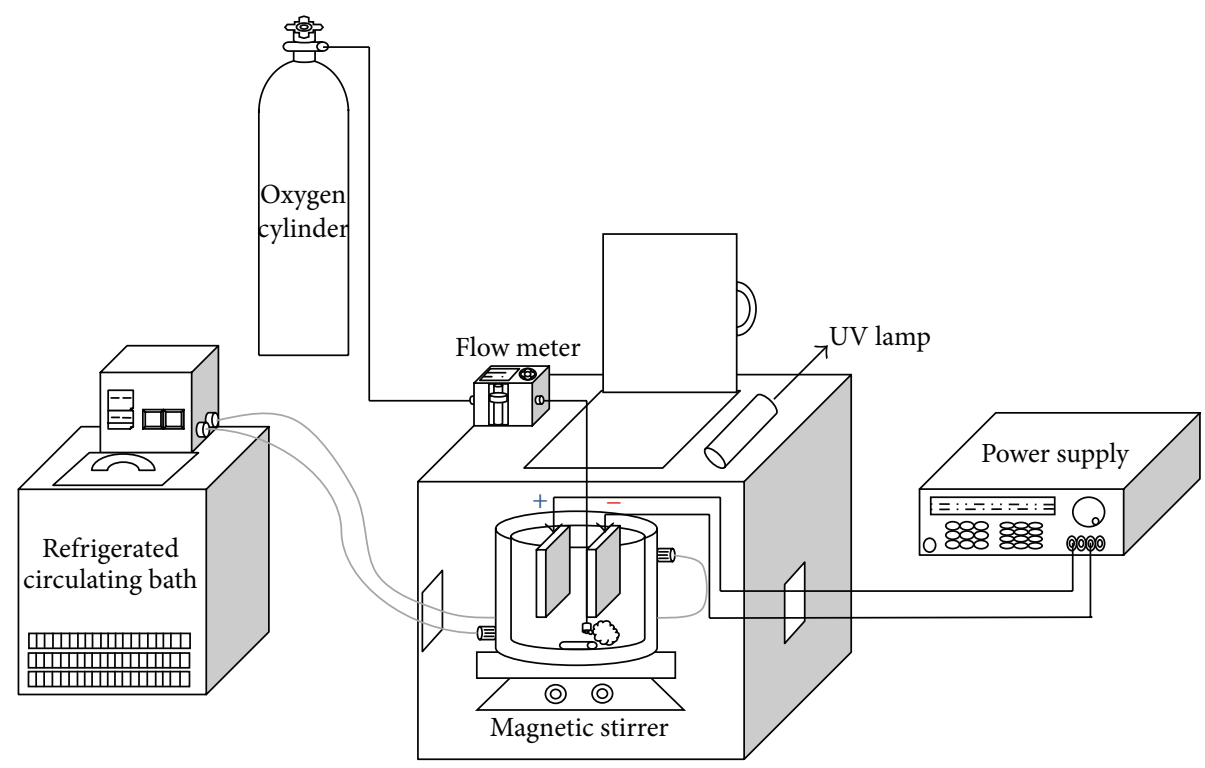

FIGURE 1: Schematic diagram of the photoelectrochemical oxidation equipment.

series, was obtained from Taiwan carbon Technology Co. Ltd. (Taichung, Taiwan).

2.2. Apparatus. Figure 1 is a schematic diagram of the photoelectrochemical system and the electrode assembly used in this work. The electrolytic reactor was a $1.0 \mathrm{~L}$ Pyrex glass vessel equipped with a water jacket and a magnetic stirrer. A magnetic stirrer bar (Suntex, SH-301, Taiwan) was spun at the center of the bottom of the reactor. The temperature of the electrolytic cell was controlled by continuously circulating water through the water jacket from a temperature controlled bath (Model BL-720, Taiwan). The assembly was connected to a direct current power source (PSM-6003, Taichung, Taiwan). A UV lamp (8 W, UV-C, $\lambda_{\max }=254 \mathrm{~nm}$, manufactured by Sankyo Denki, Tokyo, Japan) was used as a radiation source and placed above an electrolytic reactor. The UV-light intensity was measured by a Digital Ultraviolet Radiometer (Rixen Technology, Taipei, Taiwan).

2.3. Experimental and Analysis. The experiments were conducted in a close, and undivided glass vessel. For each test run, a circular container with $0.5 \mathrm{~L}$ of synthetic wastewater containing polyvinyl alcohol was used as the reactor. The ACF, graphite plate, and platinum were used as the cathodes and a platinum flat with an area of about $7.5 \mathrm{~cm}^{2}$ as the anode. The two electrodes were approximately $2 \mathrm{~cm}$ apart. The magnetic stirrer was turned on and set at $300 \mathrm{rpm}$. The ACF felt was saturated with $1000 \mathrm{mg} \mathrm{L}^{-1}$ PVA solution for $24 \mathrm{~h}$ to exclude the adsorption reaction of PVA on the ACF felt. During the electrolysis experiments, the cathode surface was fed with $\mathrm{O}_{2}$ for electrochemical reactions. Before the photoelectrochemical treatment, the $\mathrm{pH}$ of aqueous solution containing PVA was measured with $\mathrm{pH}$ meter. The photoelectrochemical treatment run lasted $120 \mathrm{~min}$ in all experiments. The $\mathrm{H}_{2} \mathrm{O}_{2}$ concentration was determined using the $\mathrm{Ti}\left(\mathrm{SO}_{4}\right)_{2}$ titration method and spectrophotometric analysis at $\lambda=410 \mathrm{~nm}$ [27]. The PVA concentration in the aqueous solutions was determined using a HACH Model DR2800 spectrophotometer (HACH Company, USA) after addition of boric acid and iodine solutions according to the procedure described by Finley [28]. In order to calculate the normalized PVA concentration was performed using the following formula:

$$
\text { Normalized PVA }=\frac{C}{C_{0}},
$$

where $C_{0}$ is the initial concentration in $\mathrm{mg} \mathrm{L}^{-1}, C$ is the concentration value at time $t$ in $\mathrm{mg} \mathrm{L}^{-1}$. All samples were measured in duplicate to ensure data reproducibility, and an additional measurement was carried out if necessary.

\section{Results and Discussion}

3.1. Comparison of Electrogeneration of $\mathrm{H}_{2} \mathrm{O}_{2}$ on Different Electrodes. $\mathrm{H}_{2} \mathrm{O}_{2}$ is often used in the oxidation of organic pollutants because of its high oxidation reduction potential (ORP), which can facilitate the degradation of organic pollutants. The previous literature reports that electrodes made from carbon materials have been used to generate $\mathrm{H}_{2} \mathrm{O}_{2}$ with good yields, for example, graphite [29], gas diffusion electrodes [30], carbon felt [31], carbon nanotube-PTFE [32], glassy carbon mesh [33], and activated carbon fiber [34]. The amount of $\mathrm{H}_{2} \mathrm{O}_{2}$ generated by the two-electron reduction of $\mathrm{O}_{2}$ on the cathode surface is an important parameter in the electrogeneration process. Apparently, the cathode material strongly affects the rate of formation of hydrogen peroxide. Therefore, it is necessary to investigate the yield of $\mathrm{H}_{2} \mathrm{O}_{2}$ in photoelectrochemical oxidation processes using different cathode materials. To evaluate their comparative performance for $\mathrm{H}_{2} \mathrm{O}_{2}$ generation, several cathode materials were 


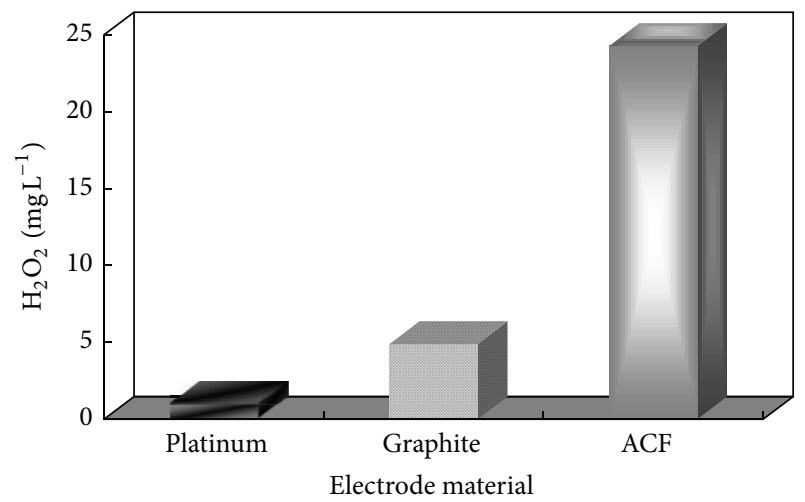

Figure 2: Effect of different electrode materials on the $\mathrm{H}_{2} \mathrm{O}_{2}$ electrogeneration. $\left(\mathrm{Na}_{2} \mathrm{SO}_{4}=0.05 \mathrm{M}, \mathrm{pH}=3\right.$, oxygen flow rate = $500 \mathrm{~cm}^{3} \mathrm{~min}^{-1}$, and current density $=10 \mathrm{~mA} \mathrm{~cm}^{-2}$ ).

used, including ACF, graphite, and platinum. Figure 2 shows a comparison of the $\mathrm{H}_{2} \mathrm{O}_{2}$ generation rates achieved using different electrode materials. As shown in this figure, $\mathrm{H}_{2} \mathrm{O}_{2}$ production rates of $1 \mathrm{mg} \mathrm{L}^{-1}, 4.9 \mathrm{mg} \mathrm{L}^{-1}$, and $24.3 \mathrm{mg} \mathrm{L}^{-1}$ were achieved after $120 \mathrm{~min}$ of electrolysis using platinum, graphite, and ACF electrodes, respectively. This finding is likely explained by the fact that the ACF electrode has a large specific surface area and a great number of mesopores, so that oxygen can be rapidly adsorbed and reduced on the cathode surface, thereby generating $\mathrm{H}_{2} \mathrm{O}_{2}$ at high rates. This observation was in agreement with another previous study [34].

\subsection{Effect of Operational Parameters on the Generation of $\mathrm{H}_{2} \mathrm{O}_{2}$}

3.2.1. Effect of Current Density. To confirm the effect of current density on the electrochemical generation of $\mathrm{H}_{2} \mathrm{O}_{2}$ on the ACF cathode, several current densities were used in acidic solutions containing $0.05 \mathrm{M} \mathrm{Na}_{2} \mathrm{SO}_{4}$. Figure 3 shows the effect of the current density on the generation of $\mathrm{H}_{2} \mathrm{O}_{2}$ for various electrolysis durations. As the duration of the electrolysis increased, concomitant increases in $\mathrm{H}_{2} \mathrm{O}_{2}$ generation were observed for all current densities (4):

$$
\mathrm{O}_{2}+2 \mathrm{H}^{+}+2 \mathrm{e}^{-} \longrightarrow \mathrm{H}_{2} \mathrm{O}_{2}
$$

After 120 min of electrolysis, the $\mathrm{H}_{2} \mathrm{O}_{2}$ concentration gradually rose for all of the current densities, eventually reaching a steady state, as shown in Figure 3. An inspection of these results shows a clear maximum in the concentration of $\mathrm{H}_{2} \mathrm{O}_{2}$ generated at a current density of $10 \mathrm{~mA} \mathrm{~cm}^{-2}$. In the cases where current densities lower than $10 \mathrm{~mA} \mathrm{~cm}^{-2}$ were applied, the $\mathrm{H}_{2} \mathrm{O}_{2}$ concentration increased with increasing current density, likely because increasing the applied current density can enhance the production rate of $\mathrm{H}_{2} \mathrm{O}_{2}$. However, the findings indicated that the $\mathrm{H}_{2} \mathrm{O}_{2}$ concentration underwent a dramatic decrease when the current density reached $12.5 \mathrm{~mA} \mathrm{~cm}^{-2}$. This finding can be ascribed to the fact that higher applied current density reflects higher applied voltage on the electrochemical system, which induces the

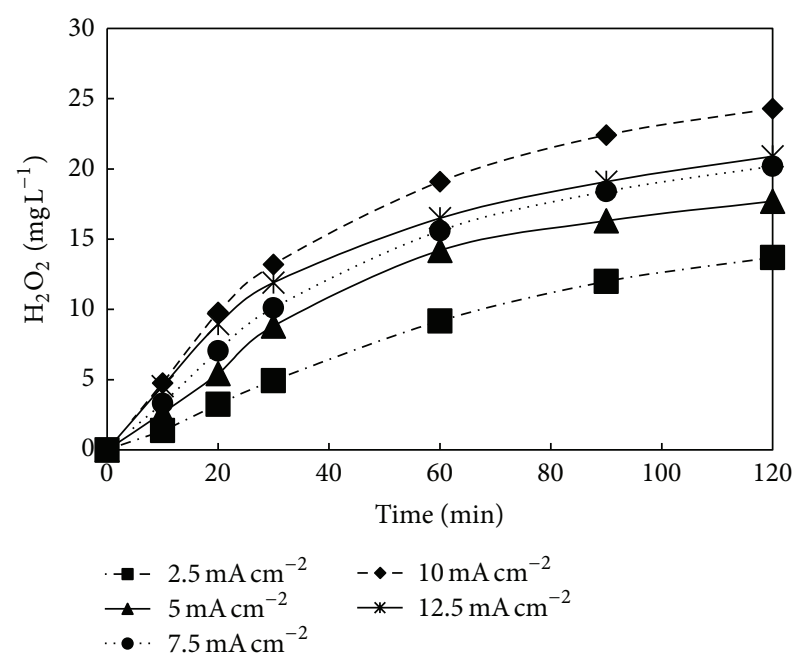

FIGURE 3: Effect of current density on the $\mathrm{H}_{2} \mathrm{O}_{2}$ electrogeneration as a function of time. $\left(\mathrm{Na}_{2} \mathrm{SO}_{4}=0.05 \mathrm{M}, \mathrm{pH}=3\right.$, and oxygen flow rate $=500 \mathrm{~cm}^{3} \mathrm{~min}^{-1}$ ).

decomposition of $\mathrm{H}_{2} \mathrm{O}_{2}$, either on the electrode or directly in the solution (5) [35]. In addition, the electrode surface reactions such as the production of oxygen and hydrogen also retard the reactions generating $\mathrm{H}_{2} \mathrm{O}_{2}$ [36]. Furthermore, a portion of the $\mathrm{H}_{2} \mathrm{O}_{2}$ produced can be anodically oxidized to yield intermediate $\mathrm{HO}_{2}^{\circ}$ radicals [37]. Consequently, a current density of $10 \mathrm{~mA} \mathrm{~cm}^{-2}$ was chosen as the optimum current density for the subsequent experiments:

$$
\begin{gathered}
\mathrm{H}_{2} \mathrm{O}_{2}+2 \mathrm{e}^{-} \longrightarrow 2 \mathrm{OH}^{-} \\
\mathrm{H}_{2} \mathrm{O}_{2} \longrightarrow \mathrm{HO}_{2}^{\cdot}+\mathrm{H}^{+}+\mathrm{e}^{-} \\
\mathrm{HO}_{2}^{\cdot} \longrightarrow \mathrm{O}_{2}+\mathrm{H}^{+}+\mathrm{e}^{-}
\end{gathered}
$$

3.2.2. Effect of Oxygen Flow Rate. The rate of $\mathrm{H}_{2} \mathrm{O}_{2}$ generation via oxygen reduction at the cathode significantly affects the treatment efficiency of photoelectrochemical oxidation processes. The effect of the oxygen flow rate on the rate of $\mathrm{H}_{2} \mathrm{O}_{2}$ electrogeneration was studied by varying the flow rate between 300 and $900 \mathrm{~cm}^{3} \mathrm{~min}^{-1}$ while keeping the current density, the initial $\mathrm{pH}$, and supporting electrolyte at $10 \mathrm{~mA} \mathrm{~cm}^{-2}, 3$, and $0.05 \mathrm{M} \mathrm{Na}_{2} \mathrm{SO}_{4}$, as shown in Table 1 . A significant increase in the $\mathrm{H}_{2} \mathrm{O}_{2}$ electrogeneration rate was observed with increases in the oxygen flow rate. After $120 \mathrm{~min}$ of electrolysis, the oxygen flow rate increased from 300 to 500,700 , and $900 \mathrm{~cm}^{3} \mathrm{~min}^{-1}$, and the $\mathrm{H}_{2} \mathrm{O}_{2}$ concentration increased from $13.7 \mathrm{mg} \mathrm{L}^{-1}$ to $24.3 \mathrm{mg} \mathrm{L}^{-1}, 25.4 \mathrm{mg} \mathrm{L}^{-1}$, and $26.1 \mathrm{~m} \mathrm{~L}^{-1}$, respectively. Table 1 illustrates that increasing the oxygen flow rate can increase the amount of dissolved oxygen in the solution, thereby accelerating the generation of hydrogen peroxide. Namely, increasing the oxygen flow rate can increase the dissolved oxygen concentration and the mass transfer rate of dissolved oxygen and finally increase the production of $\mathrm{H}_{2} \mathrm{O}_{2}$. However, above an oxygen flow rate of $500 \mathrm{~cm}^{3} \mathrm{~min}^{-1}$, the dissolved oxygen and hydrogen peroxide concentration followed a steady trend. The results 
TABLE 1: Effect of the oxygen flow rate and initial $\mathrm{pH}$ value on the $\mathrm{H}_{2} \mathrm{O}_{2}$ electrogeneration.

\begin{tabular}{lcccccccc}
\hline & \multicolumn{3}{c}{ Oxygen flow rate $\left(\mathrm{cm}^{3} \mathrm{~min}^{-1}\right)$} & \multicolumn{3}{c}{$\mathrm{pH}$} & & \\
& 300 & 500 & 700 & 900 & 2 & 3 & 4 \\
\hline $\mathrm{H}_{2} \mathrm{O}_{2}$ generation concentration $\left(\mathrm{mg} \mathrm{L}^{-1}\right)$ & 13.7 & 24.3 & 25.4 & 26.1 & 22.2 & 24.3 & 14.4 & 11 \\
\hline
\end{tabular}

implied that the electrochemical kinetics of the hydrogen peroxide production correlated well with the amount of oxygen solubility dissolved in aqueous solutions, in which the saturated solubility of oxygen in aqueous solutions was nearly achieved at the oxygen flow rate of $500 \mathrm{~cm}^{3} \mathrm{~min}^{-1}$ [38]. According to these results and economic considerations, an oxygen flow rate of $500 \mathrm{~cm}^{3} \mathrm{~min}^{-1}$ at an applied current density of $10 \mathrm{~mA} \mathrm{~cm}^{-2}$ was adequate for further study in the present work.

3.2.3. Effect of Initial $p H$. In an electrochemical oxidation process, the solution $\mathrm{pH}$ is a crucial factor for the electrogeneration of $\mathrm{H}_{2} \mathrm{O}_{2}$. In $\mathrm{H}_{2} \mathrm{O}_{2}$ production, a low $\mathrm{pH}$ is theoretically favorable for the production of $\mathrm{H}_{2} \mathrm{O}_{2}$ because the conversion of dissolved oxygen to $\mathrm{H}_{2} \mathrm{O}_{2}$ consumes protons in acidic solution. However, a low $\mathrm{pH}$ also promotes hydrogen evolution, reducing the number of active sites for generating $\mathrm{H}_{2} \mathrm{O}_{2}$. Therefore, the existence of an optimal solution $\mathrm{pH}$ might be expected. The effect of the initial $\mathrm{pH}$ value of the solution on the rate of $\mathrm{H}_{2} \mathrm{O}_{2}$ electrogeneration was investigated by varying the initial $\mathrm{pH}$ between 2 and 5 while keeping the current density, oxygen flow rate, and supporting electrolyte at $10 \mathrm{~mA} \mathrm{~cm}^{-2}, 500 \mathrm{~cm}^{3} \mathrm{~min}^{-1}$, and $0.05 \mathrm{M} \mathrm{Na}_{2} \mathrm{SO}_{4}$, as shown in Table 1. From this table, it was shown that the maximum concentration of $\mathrm{H}_{2} \mathrm{O}_{2}\left(24.3 \mathrm{mg} \mathrm{L}^{-1}\right)$ was obtained at an initial $\mathrm{pH}=3$ after $120 \mathrm{~min}$ of electrolysis. However, the accumulated concentration of $\mathrm{H}_{2} \mathrm{O}_{2}$ fell to $22.2 \mathrm{mg} \mathrm{L}^{-1}$ as the initial $\mathrm{pH}$ decreased to 2 . This finding could be explained by the fact that the oxonium ion $\left(\mathrm{H}_{3} \mathrm{O}_{2}^{+}\right)$can enhance the stability of $\mathrm{H}_{2} \mathrm{O}_{2}$ (8) [39]. At the same time, two side reactions occur at the cathode: the reduction of $\mathrm{H}_{2} \mathrm{O}_{2}$ to $\mathrm{H}_{2} \mathrm{O}$ (9) and hydrogen gas production (10) [40]. Therefore, these side reactions decreased the accumulation of $\mathrm{H}_{2} \mathrm{O}_{2}$ in the solution at lower $\mathrm{pH}$ values. Based on these results, a $\mathrm{pH}$ value of 3 was found to be the optimal condition for $\mathrm{H}_{2} \mathrm{O}_{2}$ electrogeneration:

$$
\begin{gathered}
\mathrm{H}_{2} \mathrm{O}_{2}+\mathrm{H}^{+} \longrightarrow \mathrm{H}_{3} \mathrm{O}_{2}^{+} \\
\mathrm{H}_{2} \mathrm{O}_{2}+2 \mathrm{H}^{+}+2 \mathrm{e}^{-} \longrightarrow 2 \mathrm{H}_{2} \mathrm{O} \\
2 \mathrm{H}^{+}+2 \mathrm{e}^{-} \longrightarrow \mathrm{H}_{2}
\end{gathered}
$$

3.2.4. Effect of Different Supporting Electrolytes. In electrochemical processes that consist of heterogeneous ion and electron transfer reactions, the conductivity of the solution to be treated is a significant parameter. The most common method of adjusting this parameter is to add a supporting electrolyte, which increases the solution conductivity and thus reduces energy consumption during the electrochemical process. To investigate the effect of the supporting electrolyte species on the generation of $\mathrm{H}_{2} \mathrm{O}_{2}, \mathrm{Na}_{2} \mathrm{SO}_{4}, \mathrm{NaNO}_{3}$,

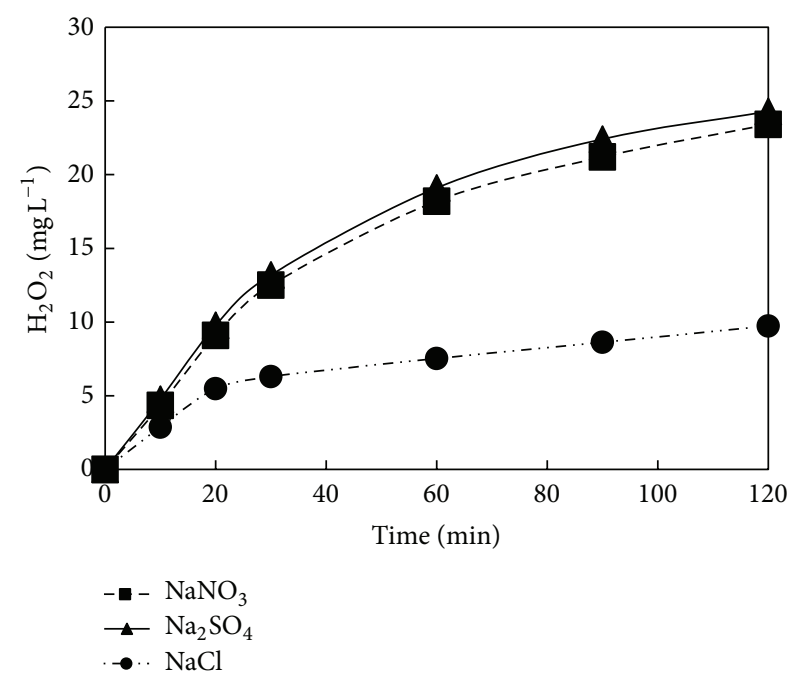

FIgURE 4: Effect of supporting electrolyte on the $\mathrm{H}_{2} \mathrm{O}_{2}$ electrogeneration as a function of time. $(\mathrm{pH}=3$, oxygen flow rate $=$ $500 \mathrm{~cm}^{3} \mathrm{~min}^{-1}$, and current density $=10 \mathrm{~mA} \mathrm{~cm}^{-2}$ ).

and $\mathrm{NaCl}$ were used as supporting electrolytes under the same conditions, as shown in Figure 4. After $120 \mathrm{~min}$ of electrolysis, we observed that $24.3 \mathrm{mg} \mathrm{L}^{-1}, 23.4 \mathrm{mg} \mathrm{L}^{-1}$, and $9.72 \mathrm{mg} \mathrm{L}^{-1}$ of $\mathrm{H}_{2} \mathrm{O}_{2}$ were generated using $\mathrm{Na}_{2} \mathrm{SO}_{4}, \mathrm{NaNO}_{3}$, and $\mathrm{NaCl}$, respectively. As it can be seen from Figure 4, the concentration of electrogenerated $\mathrm{H}_{2} \mathrm{O}_{2}$ produced in $\mathrm{NaCl}$ solution was lower than the concentrations produced in $\mathrm{NaNO}_{3}$ and $\mathrm{Na}_{2} \mathrm{SO}_{4}$. This observation could likely be explained by the fact that $\mathrm{Cl}_{2}$ formation was observed as a result of chlorine oxidation at high anodic potentials during the electrolysis process, and further oxidation of chlorine can also occur to form $\mathrm{HOCl}$ [38]. Therefore, these side reactions likely decreased the accumulation of $\mathrm{H}_{2} \mathrm{O}_{2}$ in the solution. Furthermore, the electrical conductivities of $\mathrm{SO}_{4}{ }^{2-}$ and $\mathrm{NO}_{3}{ }^{-}$solutions were greater than that of equivalentstrength $\mathrm{Cl}^{-}$solution [41]; thus, these solutions yielded greater amounts of electrogenerated $\mathrm{H}_{2} \mathrm{O}_{2}$. In addition, Zhou et al. reported higher concentrations of sodium sulfate, which could accelerate the generation of $\mathrm{H}_{2} \mathrm{O}_{2}$ and increase the pollutant removal efficiency [39]. Consequently, $\mathrm{Na}_{2} \mathrm{SO}_{4}$ was considered to be the most suitable electrolyte tested for the generation of $\mathrm{H}_{2} \mathrm{O}_{2}$.

\subsection{Removal of PVA by Photoelectrochemical Oxidation}

3.3.1. Effect of UV Irradiation in the Presence of $\mathrm{H}_{2} \mathrm{O}_{2}$. Figure 5 shows the PVA removal efficiency as a function of time for experiments conducted with UV irradiation only, $\mathrm{H}_{2} \mathrm{O}_{2}$ 


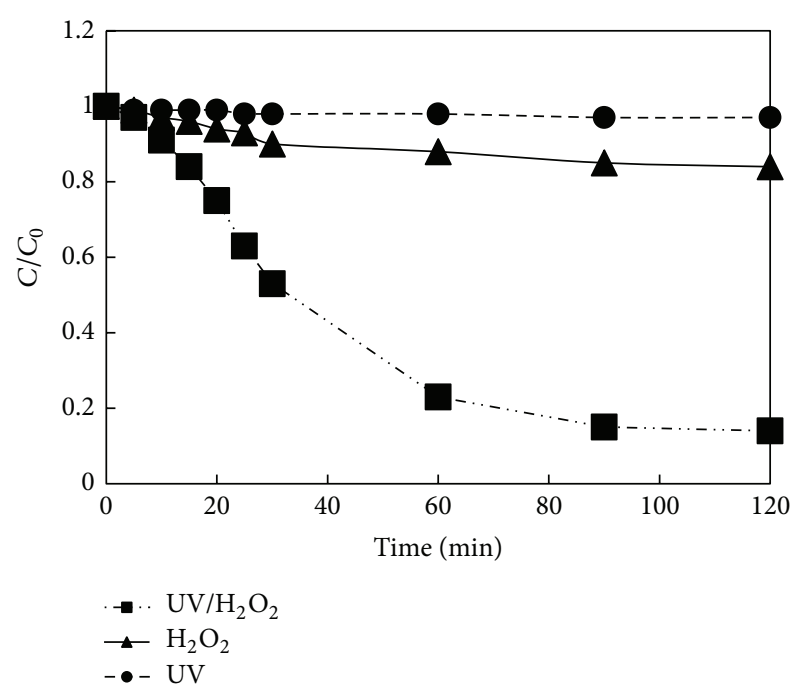

FIGURE 5: Effect of UV irradiation and $\mathrm{H}_{2} \mathrm{O}_{2}$ electrogeneration in photoelectrochemical oxidation of PVA. (PVA $=2 \mathrm{mg} \mathrm{L}^{-1}, \mathrm{Na}_{2} \mathrm{SO}_{4}=$ $0.05 \mathrm{M}, \mathrm{pH}=3$, oxygen flow rate $=500 \mathrm{~cm}^{3} \mathrm{~min}^{-1}, \mathrm{Na}_{2} \mathrm{SO}_{4}=0.05 \mathrm{M}$, and $I_{0}=0.45 \mathrm{~mW} \mathrm{~cm}^{-2}$ ).

electrogeneration without UV irradiation, and $\mathrm{H}_{2} \mathrm{O}_{2}$ electrogeneration plus UV irradiation. It can be seen that there was no significant removal of PVA with UV irradiation alone or with $\mathrm{H}_{2} \mathrm{O}_{2}$ electrogeneration in the absence of UV irradiation; the removal efficiencies for these conditions were 3\% and $16 \%$, respectively. In the case of $\mathrm{H}_{2} \mathrm{O}_{2}$ electrogeneration with UV irradiation, the PVA removal efficiency increased to $86 \%$. These results reveal that the electrogeneration of $\mathrm{H}_{2} \mathrm{O}_{2}$ in the presence of UV irradiation can form hydroxyl radicals capable of remediating solutions containing PVA. Consequently, this result proves that the photoelectrochemical oxidation method can effectively remove PVA from aqueous solutions.

3.3.2. Effect of UV Irradiation Intensity. UV light intensity determines the concentration of hydroxyl radicals generated. To evaluate the influence of UV light intensity on the removal efficiency of PVA, reaction rates were measured for various UV light intensities from 0 to $0.6 \mathrm{~mW} \mathrm{~cm}{ }^{-2}$. Figure 6 shows the effect of UV light intensity on the PVA removal efficiency. It appears that increasing UV light intensity increases the PVA removal efficiency. This result can be explained by the fact that higher UV light intensity can enhance the generation of hydroxyl radicals to remove PVA from the solution (1) $[42,43]$. On the other hand, at low UV light intensity, the rate of photolysis of $\mathrm{H}_{2} \mathrm{O}_{2}$ is limited, resulting in decreased PVA removal efficiency.

The pseudo-first-order reaction constant is linearly correlated with UV light intensity $\left(R^{2}=0.9923\right)$, which is also directly proportional to the proposed model (18), as shown in Figure 7. Therefore, the intensity of UV light is linearly correlated with the efficiency of PVA removal in this study.

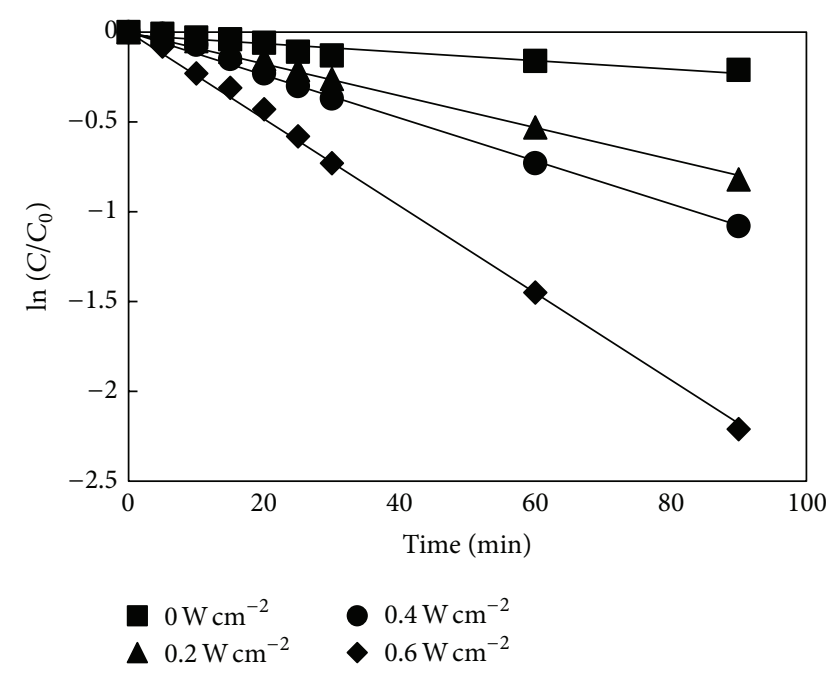

FIGURE 6: Derivation of pseudo-first-order kinetic model plot at different UV-light intensity. ( $\mathrm{PVA}=2 \mathrm{mg} \mathrm{L}^{-1}, \mathrm{pH}=3, \mathrm{Na}_{2} \mathrm{SO}_{4}=$ $0.05 \mathrm{M}$, oxygen flow rate $=500 \mathrm{~cm}^{3} \mathrm{~min}^{-1}$, and current density = $10 \mathrm{~mA} \mathrm{~cm}^{-2}$ ).

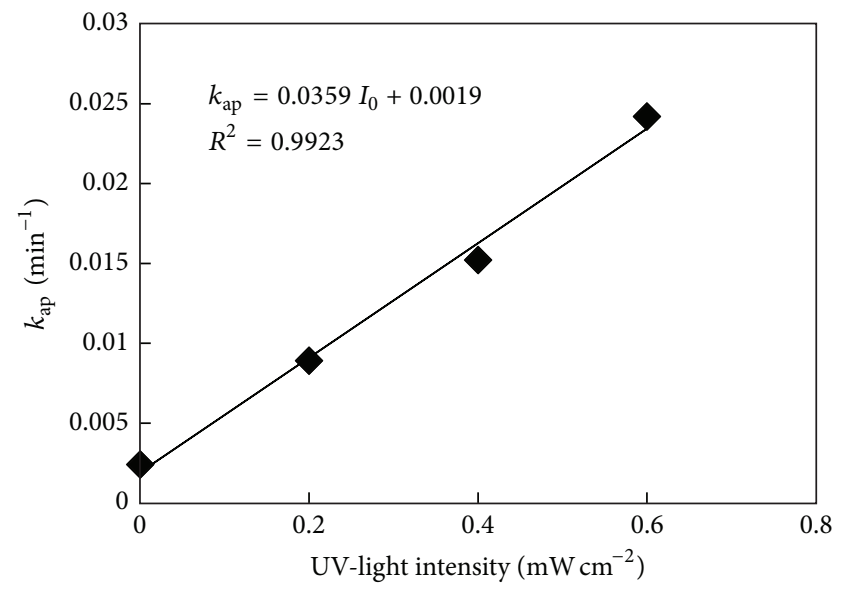

FIGURE 7: Relation between light intensity and pseudo-first-order reaction rate constant.

3.3.3. PVA Removal Kinetics of Photoelectrochemical Oxidation. The overall kinetics of PVA removal by photoelectrochemical oxidation is described by a pseudokinetic model in which the rate constant depends on the initial concentration and the UV light intensity. This model provides preliminary data for evaluating the reaction rate constant which is an important index. This constant is calculated using the following model [42]:

$$
\begin{gathered}
\mathrm{PVA}+\mathrm{OH}^{\bullet} \stackrel{k_{1}}{\rightarrow} \text { product } \\
S_{i}+\mathrm{OH}^{\bullet} \stackrel{k_{\mathrm{i}}}{\rightarrow} \text { product }_{i}
\end{gathered}
$$

where $S_{i}$ are scavenger molecules such as intermediates, excess $\mathrm{H}_{2} \mathrm{O}_{2}, \mathrm{OH}^{*}$, and $\mathrm{HO}_{2}^{*}$ [44]. 
The corresponding kinetic equations for PVA and $\mathrm{OH}^{*}$ are

$$
\begin{gathered}
\frac{d[\mathrm{PVA}]}{d t}=-k_{1}\left[\mathrm{OH}^{*}\right][\mathrm{PVA}] \\
\frac{d\left[\mathrm{OH}^{*}\right]}{d t}=\phi I_{a}-k_{1}\left[\mathrm{OH}^{*}\right][\mathrm{PVA}]-\sum k_{i}\left[\mathrm{OH}^{*}\right]\left[S_{i}\right]
\end{gathered}
$$

The steady state concentration of hydroxyl radicals can be described by (14), which is obtained by solving (13):

$$
\begin{gathered}
{\left[\mathrm{OH}^{*}\right]_{\mathrm{ss}}=\frac{\phi I_{a}}{k_{1}[\mathrm{PVA}]+\sum_{i} k_{i}\left[S_{i}\right]},} \\
I_{a}=I_{0} f_{\mathrm{H}_{2} \mathrm{O}_{2}}\left[1-\exp \left(-2.3 l\left(\varepsilon_{\mathrm{H}_{2} \mathrm{O}_{2}}\left[\mathrm{H}_{2} \mathrm{O}_{2}\right]+\varepsilon_{\mathrm{PVA}}[\mathrm{PVA}]\right)\right)\right] \\
f_{\mathrm{H}_{2} \mathrm{O}_{2}}=\frac{\varepsilon_{\mathrm{H}_{2} \mathrm{O}_{2}}\left[\mathrm{H}_{2} \mathrm{O}_{2}\right]}{\varepsilon_{\mathrm{H}_{2} \mathrm{O}_{2}}\left[\mathrm{H}_{2} \mathrm{O}_{2}\right]+\varepsilon_{\mathrm{PVA}}[\mathrm{PVA}]},
\end{gathered}
$$

where $I_{0}$ is the incident UV light intensity, $l$ is the optical path length of the system, and $\varepsilon_{\mathrm{H}_{2} \mathrm{O}_{2}}$ and $\varepsilon_{\mathrm{PVA}}$ are the molar extinction coefficients for $\mathrm{H}_{2} \mathrm{O}_{2}$ and PVA, respectively. As PVA and $\mathrm{H}_{2} \mathrm{O}_{2}$ have high absorbances in the early stages of the process, we can write

$$
\begin{gathered}
1-\exp \left(-2.3 l\left(\varepsilon_{\mathrm{H}_{2} \mathrm{O}_{2}}\left[\mathrm{H}_{2} \mathrm{O}_{2}\right]+\varepsilon_{\mathrm{PVA}}[\mathrm{PVA}]\right)\right) \approx 1, \\
{\left[\mathrm{OH}^{\bullet}\right]_{\mathrm{ss}}=\frac{\phi I_{0} f_{\mathrm{H}_{2} \mathrm{O}_{2}}}{k_{1}[\mathrm{PVA}]+\sum_{i} k_{i}\left[S_{i}\right]} .}
\end{gathered}
$$

By inserting the previous expression into (13), the following overall rate law is deduced:

$$
-\frac{d[\mathrm{PVA}]}{d t}=\frac{k_{1} \phi I_{0} f_{\mathrm{H}_{2} \mathrm{O}_{2}}}{k_{1}[\mathrm{PVA}]+\sum_{i} k_{i}\left[S_{i}\right]}[\mathrm{PVA}] .
$$

If the concentration of the substrate is high, so that $k_{1}[\mathrm{PVA}] \gg \sum_{i} k_{i}\left[S_{i}\right]$, the overall rate expression simplifies to a zero order reaction rate:

$$
-\frac{d[\mathrm{PVA}]}{d t}=\phi I_{0} f_{\mathrm{H}_{2} \mathrm{O}_{2}} .
$$

However, in the present study, the concentration of PVA is lower than that of $\mathrm{H}_{2} \mathrm{O}_{2}$; thus, $\sum_{i} k_{i}\left[S_{i}\right] \gg k_{1}[\mathrm{PVA}]$, and the overall rate expression simplifies to a pseudo-first-order reaction rate:

$$
-\frac{d[\mathrm{PVA}]}{d t}=\frac{k_{1} \phi I_{0} f_{\mathrm{H}_{2} \mathrm{O}_{2}}}{\sum_{i} k_{i}\left[S_{i}\right]}[\mathrm{PVA}]
$$

or

$$
-\frac{d[\mathrm{PVA}]}{d t}=k_{\mathrm{ap}}[\mathrm{PVA}] .
$$

The previous equation corresponds to a pseudo-firstorder reaction. The semilogarithmic graphs of PVA concentration versus time thus can be fitted with a straight
TABLE 2: Pseudo-first-order rate constants for PVA removal at various UV-light intensity.

\begin{tabular}{lcc}
\hline \multirow{2}{*}{ UV-light intensity $\left(\mathrm{mW} \mathrm{cm}^{-2}\right)$} & \multicolumn{2}{c}{ Pseudo-first-order } \\
\hline 0 & $k_{\mathrm{ap}}$ & $R^{2}$ \\
0.2 & 0.0024 & 0.9 \\
0.4 & 0.0094 & 0.992 \\
0.6 & 0.0152 & 0.994 \\
\hline
\end{tabular}

line to obtain the apparent reaction rate constant $\left(k_{\mathrm{ap}}\right)$. The conformity between experimental data and the model values was evaluated by calculating correlation coefficients $\left(R^{2}\right)$. The apparent reaction rate constants and correlation coefficients calculated from the pseudo-first-order model are listed in Table 2. Table 2 also shows that as the UV light intensity is increased, the reaction rate constant increases, and thus, the removal efficiency of PVA increases.

\section{Conclusions}

In this study, the removal of PVA from aqueous solution via photoelectrochemical oxidation was investigated in a closed batch system. We compared the electrogeneration of $\mathrm{H}_{2} \mathrm{O}_{2}$ using three cathode materials (i.e., platinum, graphite, and activated carbon fiber (ACF)) fed with oxygen. The accumulation of electrogenerated $\mathrm{H}_{2} \mathrm{O}_{2}$ using the ACF electrode was greater than the concentrations obtained using other cathode materials. Several parameters were evaluated to characterize the $\mathrm{H}_{2} \mathrm{O}_{2}$ electrogeneration, such as current density, oxygen flow rate, solution $\mathrm{pH}$, and the type of supporting electrolyte used. The results indicated that the optimal conditions for $\mathrm{H}_{2} \mathrm{O}_{2}$ electrogeneration were a current density of $10 \mathrm{~mA} \mathrm{~cm}^{-2}$, an oxygen flow rate of $500 \mathrm{~cm}^{3} \mathrm{~min}^{-1}$, and $\mathrm{pH}=3$. The addition of $0.05 \mathrm{M} \mathrm{Na}_{2} \mathrm{SO}_{4}$ as a supporting electrolyte also resulted in rapid $\mathrm{H}_{2} \mathrm{O}_{2}$ electrogeneration. The PVA removal efficiencies achieved under these conditions were $3 \%, 16 \%$, and $86 \%$ using $\mathrm{UV}, \mathrm{H}_{2} \mathrm{O}_{2}$ electrogeneration, and $\mathrm{UV} / \mathrm{H}_{2} \mathrm{O}_{2}$ electrogeneration, respectively. A UV light intensity of $0.6 \mathrm{~mW} \mathrm{~cm}^{-2}$ was found to produce the highest rate of PVA removal in the present study. A simple kinetic model was proposed which confirmed the suitability of pseudo-first-order reaction. Reaction rate constant $\left(k_{\mathrm{ap}}\right)$ was dependent on the UV light intensity, and the pseudofirst-order constant was also directly proportional to UV light intensity. Under these conditions, the maximum PVA removal efficiency was found to be $91 \%$.

\section{Conflict of Interests}

The authors declare that there is no conflict of interests with any financial organization regarding the material discussed in this study. 


\section{Acknowledgment}

The authors would like to thank the National Science Council of Taiwan, ROC, for financially supporting this study under contract number NSC101-2628-E-241-013-MY3.

\section{References}

[1] X. Zhu, M. Tong, S. Shi, H. Zhao, and J. Ni, "Essential explanation of the strong mineralization performance of boron-doped diamond electrodes," Environmental Science and Technology, vol. 42, no. 13, pp. 4914-4920, 2008.

[2] M. Zhou, Z. Wu, X. Ma, Y. Cong, Q. Ye, and D. Wang, "A novel fluidized electrochemical reactor for organic pollutant abatement," Separation and Purification Technology, vol. 34, no. 1-3, pp. 81-88, 2004.

[3] L. Wei, H. Zhu, X. Mao, and F. Gan, "Electrochemical oxidation process combined with UV photolysis for the mineralization of nitrophenol in saline wastewater," Separation and Purification Technology, vol. 77, no. 1, pp. 18-25, 2011.

[4] D. R. Stapleton, I. K. Konstantinou, D. G. Hela, and M. Papadaki, "Photolytic removal and mineralisation of 2halogenated pyridines," Water Research, vol. 43, no. 16, pp. 3964-3973, 2009.

[5] O. Legrini, E. Oliveros, and A. M. Braun, "Photochemical processes for water treatment," Chemical Reviews, vol. 93, no. 2, pp. 671-698, 1993.

[6] M. Panizza and G. Cerisola, "Electrochemical generation of $\mathrm{H}_{2} \mathrm{O}_{2}$ in low ionic strength media on gas diffusion cathode fed with air," Electrochimica Acta, vol. 54, no. 2, pp. 876-878, 2008.

[7] D. Georgiou, P. Melidis, A. Aivasidis, and K. Gimouhopoulos, "Degradation of azo-reactive dyes by ultraviolet radiation in the presence of hydrogen peroxide," Dyes and Pigments, vol. 52, no. 2, pp. 69-78, 2002.

[8] X. Wang, H. Zhao, X. Quan, Y. Zhao, and S. Chen, "Visible light photoelectrocatalysis with salicylic acid-modified $\mathrm{TiO}_{2}$ nanotube array electrode for p-nitrophenol degradation," Journal of Hazardous Materials, vol. 166, no. 1, pp. 547-552, 2009.

[9] L. Zhou, Z. Hu, C. Zhang, Z. Bi, T. Jin, and M. Zhou, "Electrogeneration of hydrogen peroxide for electro-Fenton system by oxygen reduction using chemically modified graphite felt cathode," Separation and Purification Technology, vol. 111, pp. 131-136, 2013.

[10] M. Skoumal, R. M. Rodríguez, P. L. Cabot et al., "ElectroFenton, UVA photoelectro-Fenton and solar photoelectroFenton degradation of the drug ibuprofen in acid aqueous medium using platinum and boron-doped diamond anodes," Electrochimica Acta, vol. 54, no. 7, pp. 2077-2085, 2009.

[11] A. Altin, "An alternative type of photoelectro-Fenton process for the treatment of landfill leachate," Separation and Purification Technology, vol. 61, no. 3, pp. 391-397, 2008.

[12] S. Irmak, H. I. Yavuz, and O. Erbatur, "Degradation of 4chloro-2-methylphenol in aqueous solution by electro-Fenton and photoelectro-Fenton processes," Applied Catalysis B, vol. 63, no. 3-4, pp. 243-248, 2006.

[13] A. Model, E. Bustos, K. Esquivel, L. A. Godinez, and Y. Meas, "Electrochemical incineration of phenolic compounds from the hydrocarbon industry using boron-doped diamond electrodes," International Journal of Photoenergy, vol. 2012, Article ID 681875, 6 pages, 2012.
[14] C.-T. Wang, J.-L. Hu, W.-L. Chou, and Y.-M. Kuo, "Removal of color from real dyeing wastewater by Electro-Fenton technology using a three-dimensional graphite cathode," Journal of Hazardous Materials, vol. 152, no. 2, pp. 601-606, 2008.

[15] J. Jia, J. Yang, J. Liao, W. Wang, and Z. Wang, "Treatment of dyeing wastewater with ACF electrodes," Water Research, vol. 33, no. 3, pp. 881-884, 1999.

[16] C.-T. Wang, W.-L. Chou, M.-H. Chung, and Y.-M. Kuo, “COD removal from real dyeing wastewater by electro-Fenton technology using an activated carbon fiber cathode," Desalination, vol. 253, no. 1-3, pp. 129-134, 2010.

[17] W. L. Chou, L. S. Chen, C. T. Wang, and S. R. Lee, "ElectroFenton removal of polyvinyl alcohol from aqueous solutions using activated carbon fiber cathode," Fresenius Environmental Bulletin, vol. 21, no. 12, pp. 3735-3742, 2012.

[18] J. Veres, S. Ogier, G. Lloyd, and D. De Leeuw, "Gate insulators in organic field-effect transistors," Chemistry of Materials, vol. 16, no. 23, pp. 4543-4555, 2004.

[19] J. A. Giroto, R. Guardani, A. C. S. C. Teixeira, and C. A. O. Nascimento, "Study on the photo-Fenton degradation of polyvinyl alcohol in aqueous solution," Chemical Engineering and Processing, vol. 45, no. 7, pp. 523-532, 2006.

[20] J. G. Lim and D. H. Park, "Degradation of polyvinyl alcohol by Brevibacillus laterosporus: metabolic pathway of polyvinyl alcohol to acetate," Journal of Microbiology and Biotechnology, vol. 11, no. 6, pp. 928-933, 2001.

[21] S. H. Bossmann, E. Oliveros, S. Göb et al., "Degradation of polyvinyl alcohol (PVA) by homogeneous and heterogeneous photocatalysis applied to the photochemically enhanced Fenton reaction," Water Science and Technology, vol. 44, no. 5, pp. 257262, 2001.

[22] A. Grönroos, P. Pirkonen, J. Heikkinen, J. Ihalainen, H. Mursunen, and H. Sekki, "Ultrasonic depolymerization of aqueous polyvinyl alcohol," Ultrasonics Sonochemistry, vol. 8, no. 3, pp. 259-264, 2001.

[23] S. J. Zhang and H. Q. Yu, "Radiation-induced degradation of polyvinyl alcohol in aqueous solutions," Water Research, vol. 38, no. 2, pp. 309-316, 2004.

[24] S. K. Behera, J.-H. Kim, X. Guo, and H.-S. Park, "Adsorption equilibrium and kinetics of polyvinyl alcohol from aqueous solution on powdered activated carbon," Journal of Hazardous Materials, vol. 153, no. 3, pp. 1207-1214, 2008.

[25] W.-L. Chou, "Removal and adsorption characteristics of polyvinyl alcohol from aqueous solutions using electrocoagulation," Journal of Hazardous Materials, vol. 177, no. 1-3, pp. 842850, 2010.

[26] W.-L. Chou, C.-T. Wang, C.-W. Hsu, K.-Y. Huang, and T.-C. Liu, "Removal of total organic carbon from aqueous solution containing polyvinyl alcohol by electrocoagulation technology," Desalination, vol. 259, no. 1-3, pp. 103-110, 2010.

[27] M. Sudoh, H. Kitaguchi, and K. Koide, "Electrochemical production of hydrogen peroxide by reduction of oxygen," Journal of Chemical Engineering of Japan, vol. 18, no. 5, pp. 409-414, 1985.

[28] J. H. Finley, "Spectrophotometric determination of polyvinyl alcohol in paper coatings," Analytical Chemistry, vol. 33, no. 13, pp. 1925-1927, 1961.

[29] M. Panizza and M. A. Oturan, "Degradation of Alizarin Red by electro-Fenton process using a graphite-felt cathode," Electrochimica Acta, vol. 56, no. 20, pp. 7084-7087, 2011. 
[30] Y. Y. Chu, Y. Qian, W. J. Wang, and X. L. Deng, "A dual-cathode electro-Fenton oxidation coupled with anodic oxidation system used for 4-nitrophenol degradation," Journal of Hazardous Materials, vol. 199-200, pp. 179-185, 2012.

[31] I. Sirés, E. Guivarch, N. Oturan, and M. A. Oturan, "Efficient removal of triphenylmethane dyes from aqueous medium by in situ electrogenerated Fenton's reagent at carbon-felt cathode," Chemosphere, vol. 72, no. 4, pp. 592-600, 2008.

[32] A. R. Khataee, M. Zarei, and L. Moradkhannejhad, "Application of response surface methodology for optimization of azo dye removal by oxalate catalyzed photoelectro-Fenton process using carbon nanotube-PTFE cathode," Desalination, vol. 258, no. 1-3, pp. 112-119, 2010.

[33] Y. B. Xie and X. Z. Li, "Interactive oxidation of photoelectrocatalysis and electro-Fenton for azo dye degradation using $\mathrm{TiO}_{2}$-Ti mesh and reticulated vitreous carbon electrodes," Materials Chemistry and Physics, vol. 95, no. 1, pp. 39-50, 2006.

[34] H. Lei, H. Li, Z. Li et al., "Electro-Fenton degradation of cationic red X-GRL using an activated carbon fiber cathode," Process Safety and Environmental Protection, vol. 88, no. 6, pp. 431-438, 2010.

[35] E. Brillas, J. C. Calpe, and J. Casado, "Mineralization of 2,4-D by advanced electrochemical oxidation processes," Water Research, vol. 34, no. 8, pp. 2253-2262, 2000.

[36] S.-H. Yuan and X.-H. Lu, "Comparison treatment of various chlorophenols by electro-Fenton method: relationship between chlorine content and degradation," Journal of Hazardous Materials, vol. 118, no. 1-3, pp. 85-92, 2005.

[37] C. A. Martínez-Huitle and E. Brillas, "Decontamination of wastewaters containing synthetic organic dyes by electrochemical methods: a general review," Applied Catalysis B, vol. 87, no. 3-4, pp. 105-145, 2009.

[38] A. Özcan, Y. Şahin, A. Savaş Koparal, and M. A. Oturan, "Carbon sponge as a new cathode material for the electroFenton process: comparison with carbon felt cathode and application to degradation of synthetic dye basic blue 3 in aqueous medium," Journal of Electroanalytical Chemistry, vol. 616, no. 1-2, pp. 71-78, 2008.

[39] M. Zhou, Q. Yu, L. Lei, and G. Barton, "Electro-Fenton method for the removal of methyl red in an efficient electrochemical system," Separation and Purification Technology, vol. 57, no. 2, pp. 380-387, 2007.

[40] W.-P. Ting, M.-C. Lu, and Y.-H. Huang, "Kinetics of 2,6dimethylaniline degradation by electro-Fenton process," Journal of Hazardous Materials, vol. 161, no. 2-3, pp. 1484-1490, 2009.

[41] H. Golnabi, M. R. Matloob, M. Bahar, and M. Sharifian, "Investigation of electrical conductivity of different water liquids and electrolyte solutions," Iranian Physical Journal, vol. 3, no. 2, pp. 24-28, 2009.

[42] N. Modirshahla and M. A. Behnajady, "Photooxidative degradation of Malachite Green (MG) by $\mathrm{UV} / \mathrm{H}_{2} \mathrm{O}_{2}$ : influence of operational parameters and kinetic modeling," Dyes and Pigments, vol. 70, no. 1, pp. 54-59, 2006.

[43] M. Muruganandham and M. Swaminathan, "Photochemical oxidation of reactive azo dye with UV- $\mathrm{H}_{2} \mathrm{O}_{2}$ process," Dyes and Pigments, vol. 62, no. 3, pp. 269-275, 2004.

[44] N. Daneshvar, M. Rabbani, N. Modirshahla, and M. A. Behnajady, "Critical effect of hydrogen peroxide concentration in photochemical oxidative degradation of C.I. Acid Red 27 (AR27)," Chemosphere, vol. 56, no. 10, pp. 895-900, 2004. 

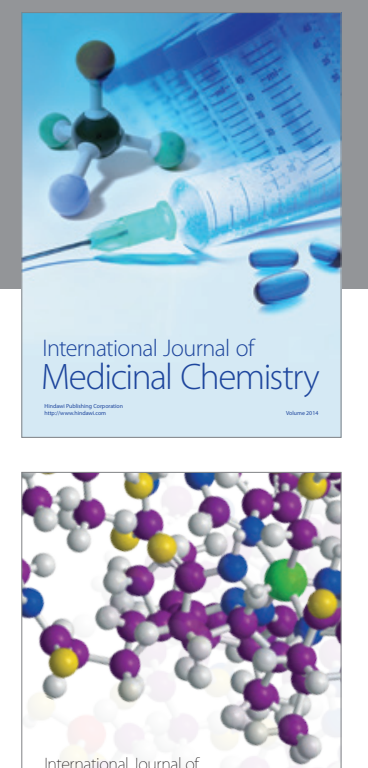

\section{Carbohydrate} Chemistry

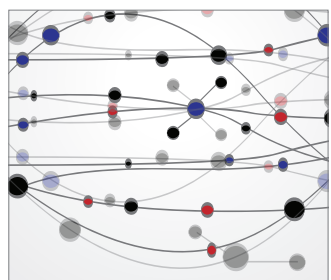

The Scientific World Journal
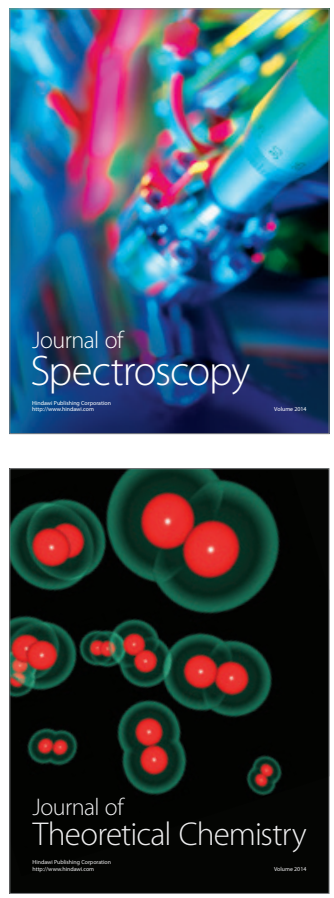
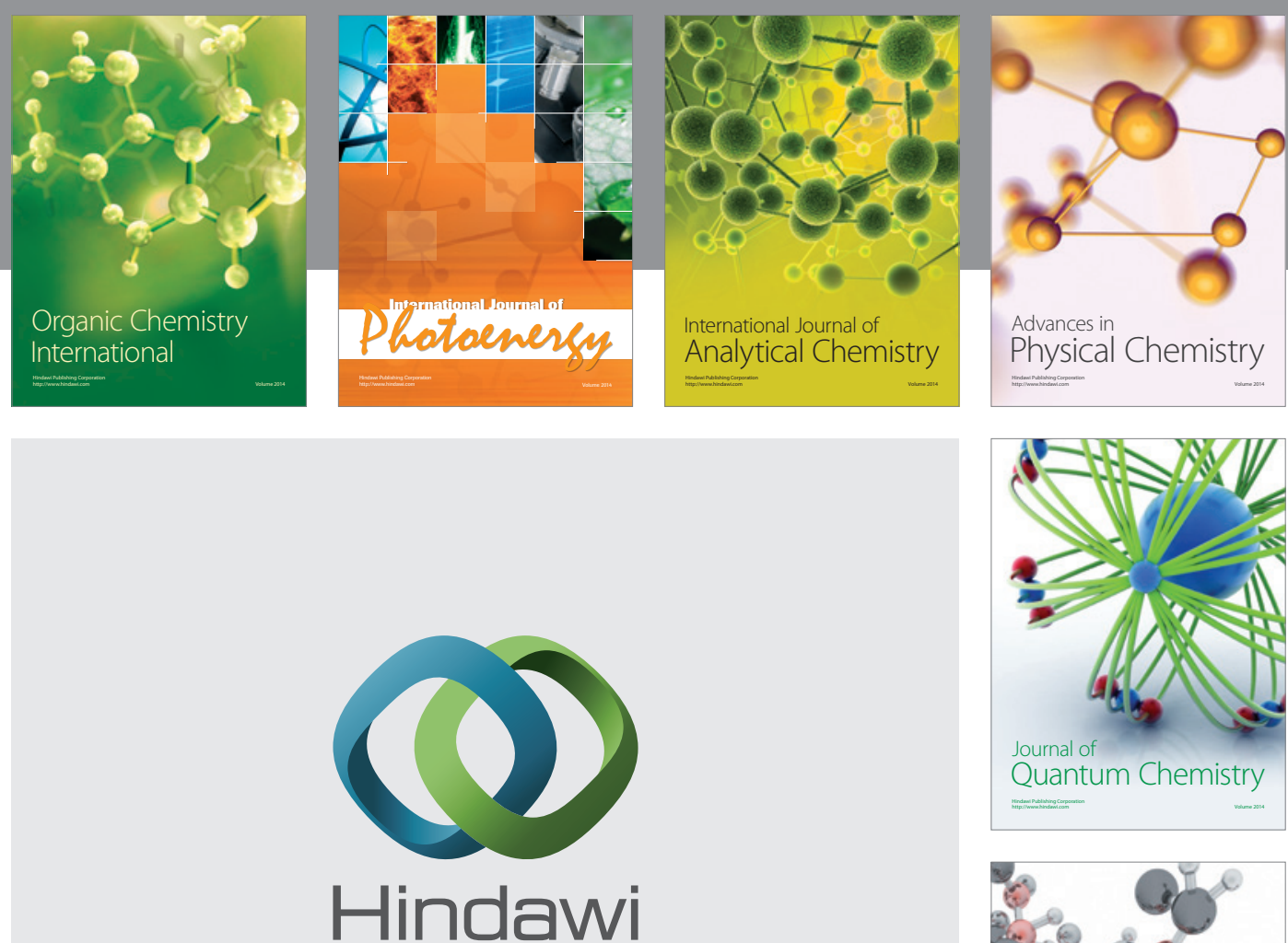

Submit your manuscripts at

http://www.hindawi.com

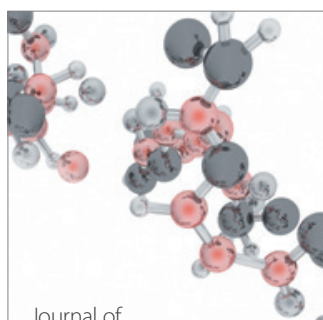

Analytical Methods

in Chemistry

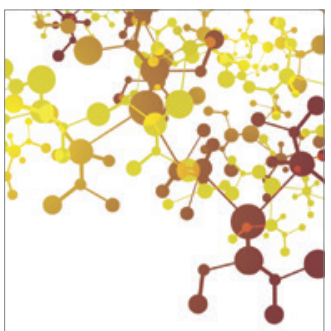

Journal of

Applied Chemistry

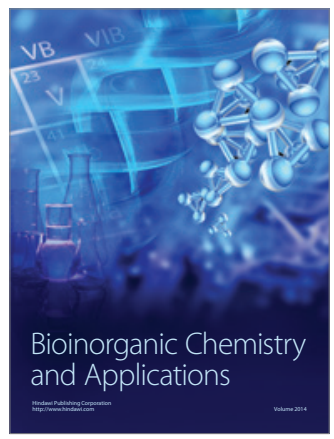

Inorganic Chemistry
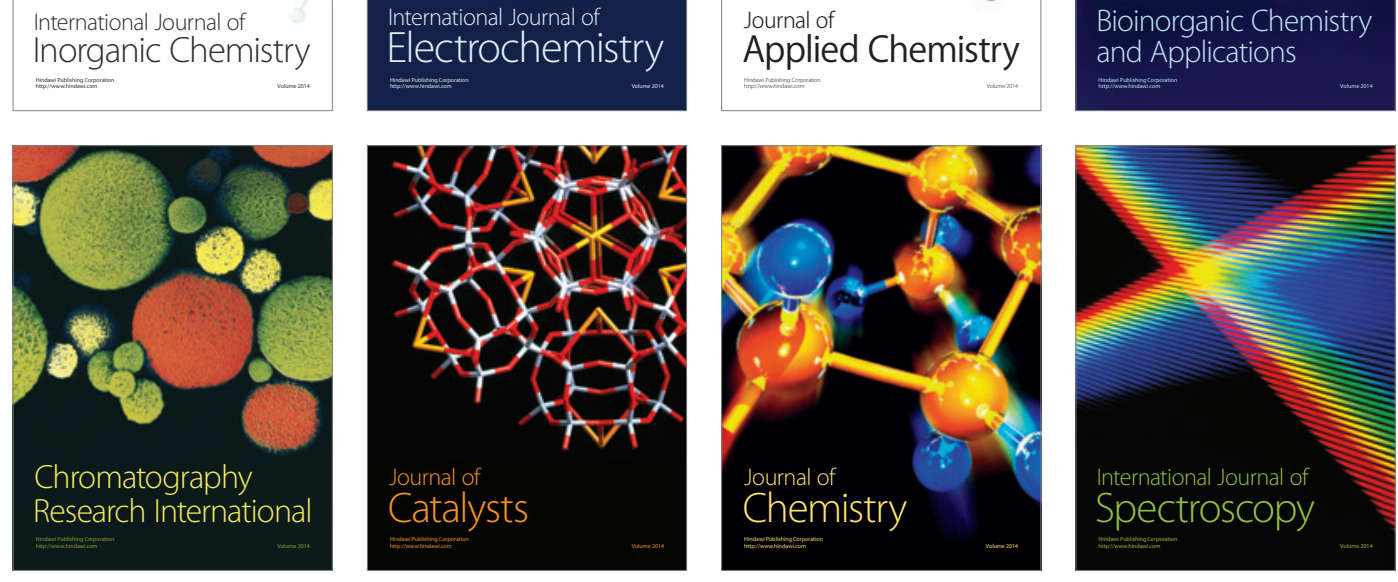